\title{
The DNA extraction from the pulp dentine complex of both with and without carious
}

\author{
A. Corte-Real ${ }^{a, *}$, L. Andrade ${ }^{b}$, M.J. Anjos ${ }^{b}$, M. Carvalho ${ }^{\text {b }}$, \\ M.C. Vide ${ }^{\mathrm{b}}$, F. Corte-Real ${ }^{\mathrm{c}}$, D.N. Vieira ${ }^{\mathrm{c}}$ \\ ${ }^{\text {a }}$ Faculty of Medicine. University of Coimbra. Portugal \\ ${ }^{\mathrm{b}}$ Department of Forensic Genetics, Coimbra Delegation, National Institute of Legal Medicine, Portugal \\ ${ }^{\mathrm{c}}$ National Institute of Legal Medicine, Portugal
}

\begin{abstract}
The main objective of this paper is to show that, despite some adverse forensic condition such as degraded human body remains and exhumed material, the dentine (in pulp dentine complex) keeps, in the majority of cases, its integrity. In this study, we use a sample of 30 human teeth (both with and without carious) after extraction during dental treatment. We analyze 15 STRs and both high-variable regions I and II of mitochondrial DNA. Each tooth was prepared using a technique that comprises the mechanic removal of the enamel, central pulp and cement. The DNA extraction was carried out with a commercial kit, but the protocol was adjusted according to the specificities of the sample. This procedure has allowed us to obtain a genetic profile of mitochondria DNA in all the samples as well as to define a profile of STRs in some of them. (C) 2006 Elsevier B.V. All rights reserved.
\end{abstract}

Keywords: Pulp-dentine-complex; Forensic DNA

\section{Introduction}

The teeth differ in form and size but have similar histological structure. The dentine is a connective tissue that forms the major structural axis of the tooth and is hardly exposed to the oral environment. The dentine on the crow of the tooth is covered by enamel. The enamel has an ectodermic origin and is an extremely mineralized tissue. Furthermore, it is an acellular and avascular structure, without nerves.

\footnotetext{
* Corresponding author. Tel.: +351 916131213; fax: +351 239820549.

E-mail address: a_cortereal@yahoo.com (A. Corte-Real).
} 
The root dentine is covered by the cement, another type of calcified connective tissue.

As the odontoblastic process is inside the dentine, the pulp and the dentine define a structural unit. Additionally, as the pulp keeps the dentine vitality and the dentine protects the pulp, they define a functional unit. Finally, both the dentine and the pulp have the same embryonic origin [1]. These three characteristics allow the dentine and pulp to form an integrated structure named the pulp dentine complex.

The mature odontoblasts are aligned along one unique layer of columnar cells, with the odontoblastic extension facing the exterior (dentin) and the cellular body facing the interior (pulp).

\section{Materials and methods}

\subsection{Sample and sample preparation}

Teeth $(n=30)$ from Portuguese aged 18-25 years were obtained from dentist immediately after extraction in an orthodontic treatment. We included both unrestored teeth and teeth with carious lesions and amalgam dental fillings. Control samples were obtained from all the donors.

The teeth were divided into five different experimental conditions: immersion in sweet and sea water, stored approximately $10 \mathrm{~cm}$ deep in garden soil, kept at room temperature, and finally included in cotton with alcohol and burned [2]. The teeth are placed for periods ranging from 1 week to 2 years.

The teeth were washed in sodium hypochlorite commercial bleach, mechanically cleaned, and washed in sterile distilled water. Using a diamond cutting disc, the entire enamel and the superficial lower of the root, the cement, were removed. The teeth were fragmented by transversal section [3]. The pulp was removed using a fine spoon excavator, and the dentine was isolated and cryogenic ground [4].

\subsection{Extraction}

DNA extraction from dentine was performed using the commercial kit Puregene ${ }^{\circledR}$ DNA Purification System (PE Gentra). We had to adjust the protocol according to the specificities of the study: we used $0.02 \mathrm{~g}$ of dentine powder, put in the bath at $55{ }^{\circ} \mathrm{C}$ overnight to a better dissolution of protein, and we dried the pellet overnight before hydration of DNA.

\subsection{Nuclear DNA amplification}

Amplification of autosomic STRs (AmpFlSTR ${ }^{\circledR}$ Identifiler $^{\mathrm{TM}}$ PCR Amplification KitApplied Biosystems) was made according to the kits' instructions.

\subsection{Mitochondrial DNA amplification}

Hypervariable regions (HVRI: L15997-H16395; HVRII: L047-H408) were amplified with primers and amplification conditions according to Wilson et al. [5], using Taq Gold. Amplified fragments were purified by MicroSpin Sephadex G50.

Detection of amplified product was carried out using an ABI Prism 3100 automatic sequencer. 


\subsection{Cycle sequencing and electrophoresis}

Sequencing reactions were performed in both directions (forward and reverse), using the ABI Prism dRhodamine Terminator Cycle Sequencing Ready Reaction Kit (Applied Biosystems), with the same primers used in amplification. Sequenced product was purified by $\mathrm{MgCl}_{2}$ /ethanol precipitation and analyzed in an ABI Prism 3100 Avant automatic sequencer.

\section{Results}

Regarding the older samples at room temperature, sweet water and soil garden, we did not find all STRs. In some of the samples in sweet water, during 1-6 months, we also did not find all STRs. Finally, in the sample placed in soil garden for 2 years, it was not possible to identify any STRs. In all remaining samples, the STR identification was possible.

This procedure has allowed us to obtain a genetic profile of mitochondrial DNA in all the samples.

\section{Discussion}

In this preliminary study, we analyzed 30 human teeth, both with and without carious, both unrestored teeth and with amalgam dental fillings. We created five different experimental conditions for periods ranging from 1 week to 2 years $[6,7]$.

We used only the dentine in a pulp dentine complex. The extraction of DNA used a commercial kit but was adjusted according to the specificities of the study.

Both these procedures have allowed us to define a genetic profile of mitochondrial DNA in all the samples as well as to define a profile of STRs in some of them.

In the oldest samples kept in sweet water, garden soil and room temperature, it was not possible to identify all the STR profiles.

The tooth, essentially the dentine, is a valuable source of DNA for identification in forensic case works. The odontoblasts have their process in the dentine, which is partially preserved from the aggressions of the environment.

\section{References}

[1] M.E.F. Gómez, A.C. Muñoz, Histologia y embriologia bucodental, Ed Medica Panamericana.

[2] A.A. García, et al., Effect of environmental factors on PCR-DNA analysis from dental pulp, Int. J. Legal Med. 109 (1996) $125-129$.

[3] B.C. Smith, et al., A systematic approach to the sampling of dental DNA, J. Forensic Sci. 38 (5) (1993) 1194-1209.

[4] R.M. Gaytmenn, S.D. Sweet, Quantification of forensic DNA from various regions of human teeth, J. Forensic Sci. 48 (3) (2003) 622-625.

[5] M.R. Wilson, et al., Validation of mitochondrial DNA sequencing for forensic casework analysis, Int. J. Legal Med. 105 (1995) 68-74.

[6] R.J. Streighner, M. Holland, Amplification and sequencing of mitochondrial and in forensic casework, Methods Mol. Biol. 98 (1998) 213-223.

[7] H. Mórnstad, et al., Demonstration and semi-quantification of mtDNA from human dentine and its relation to age, Int. J. Legal Med. 112 (1999) 98-100. 